\title{
ANTIBACTERIAL EFFICACY OF INTRACANAL MEDICAMENTS ON BACTERIAL BIOFILM: A CRITICAL REVIEW
}

\author{
Carlos ESTRELA ${ }^{1}$, Gilson Blitzkow SYDNEY², José Antonio Poli FIGUEIREDO ${ }^{3}$, Cyntia Rodrigues de Araújo ESTRELA ${ }^{4}$
}

1- DDS, MSc, PhD, Chairman and Professor of Endodontics, Department of Oral Science, Federal University of Goiás, Goiânia, GO, Brazil.

2- DDS, MSc, PhD, Chairman and Professor of Endodontics, Department of Endodontics, Federal University of Paraná, Curitiba, PR, Brazil.

3- DDS, MSc, PhD, Reader in Endodontology, Dean of the Post-graduate Program in Dentistry, Pontifical Catholic University of Rio Grande do Sul, Porto Alegre, RS, Brazil.

4- DDS, MSc, PhD, Biological Science Institute, Federal University of Goiás, Goiânia, GO, Brazil.

Correspondence Address: Prof. Carlos Estrela - Centro de Ensino e Pesquisa Odontológica do Brasil - Rua C-245, Quadra 546, Lote 9, Jardim América Goiânia -GO - 74.290-200, Brasil - e-mail: estrela3@terra.com.br

Received: January 04, 2008 - Modification: May 25, 2008 - Accepted: May 27, 2008

\begin{abstract}
T he purpose of this paper is to discuss critically the antibacterial efficacy of intracanal medicaments on bacterial biofilm. Longitudinal studies were evaluated by a systematic review of English-language articles retrieved from electronic biomedical journal databases (MEDLINE, EMBASE, CENTRAL) and handsearching records, using different matches of keywords for root canal biofilm, between 1966 and August 1 $^{\text {st }}$, 2007. The selected articles were identified from titles, abstracts and full-text articles by two independent reviewers, considering the tabulated inclusion and exclusion criteria. Disagreements were resolved by consensus. The search retrieved 91 related articles, of which $8.8 \%$ referred to in vivo studies demonstrating the lack of efficacy of endodontic therapy on bacterial biofilm. Intracanal medicaments were found to have a limited action against bacterial biofilm.
\end{abstract}

Key words: Biofilm. Intracanal medicaments. Antimicrobial efficacy.

\section{INTRODUCTION}

The principle of a treatment to reach favorable outcomes in endodontic infection management requires the recognition of the problem and the removal of the etiological factors. The microenvironment of root canal presents excellent conditions to establish microbial growth ${ }^{30}$.

The success of infected root canal therapy is influenced by discrepancy gradients of microorganisms between the endodontic biofilm and the planktonic suspension ${ }^{11}$. The phases for the microbial community to develop a biofilm and colonize the environment may sometimes be unusual, but basically occur with the same sequence of developmental steps: deposition of a conditioning film, adhesion and colonization of planktonic microorganisms in a polymeric matrix, co-adhesion of other organisms, and detachment of biofilm microorganisms into their surroundings ${ }^{8,42}$.

Reduction of endodontic microbiota has been achieved by a series of antimicrobial strategies that include root canal preparation, irrigating solutions, intracanal dressing, and root canal filling. However, innumerous published articles on endodontic infection control are motive of controversy ${ }^{1,9-}$ $11,16,19,24,26,35,39$. Several studies have been developed with different bacterial biofilm models to test the antimicrobial effectiveness of endodontic medicaments ${ }^{1,9-11,16,19,24,26,35,39}$. Investigations have shown either antimicrobial success ${ }^{9}$ or failure ${ }^{5,11,30}$ of intracanal medicaments on bacterial biofilm, as well as the presence of biofilm on the entire external root apex surfaces in teeth with pulp necrosis and radiographically visible periapical lesions ${ }^{26}$. The susceptibility of oral bacterial biofilm to antimicrobial agents indicates the need to reproduce in vivo conditions where bacteria grow as biofilm on tooth surfaces ${ }^{45}$.

Evidence-based dentistry involving systematic reviews or meta-analyses has been the ultimate goal to integrate the best available research evidence with clinical experience. In this context, it is important to make a critical analysis of therapeutic protocols for the management of bacterial biofilm. The requirement for its development includes studies in human subjects with definite clinical issues, using a critical longitudinal analysis of published articles. The focus on answering clinical questions can be structured by means of problem, intervention, comparison and outcome.

Uncountable investigations ${ }^{1-5,7,9,12-15,18,20,22,23,26,27,31-34,38,39,44}$ about the antimicrobial potential of intracanal medicaments on bacterial biofilm have shown contradictory results, but 
the clinical question on how to eliminate the endodontic bacterial biofilm remains unclear. Spratt, et al. ${ }^{39}(2001)$ verified the bactericidal effect of $2.25 \% \mathrm{NaOCl}, 0.2 \%$ chlorhexidine, $10 \%$ iodine or phosphate buffered saline on single-species biofilms ( $P$. intermedia, P. micros, $S$. intermedius, F. nucleatum and E. faecalis) derived from a range of root canal isolates. The efficacy of a particular agent was dependent on the nature of the organism in the biofilm and on the contact time. $\mathrm{NaOCl}$ was generally the most effective agent followed by iodine. However, the clinical effectiveness of these agents must be evaluated in the light of the complexity of root canal anatomy and polymicrobial nature of root canal infections. Abdullah, et al. ${ }^{1}$ (2005)

TABLE 1- Keywords used in several combinations for the search strategy

1. apical biofilm or,

2. apical biofilms or,

3. endodontic biofilm or,

4. endodontic biofilms or,

5. biofilm and root canal or,

6. biofilms and root canal or,

7. periapical biofilm or,

8. periapical biofilms or,

9. endodontic bacterial plaque or,

10. endodontics bacterial plaque or,

11. endodontic dental plaque or,

12. endodontics dental plaque or,

13. refractory endodontic plaque or,

14. biofilm and intracanal medicaments or,

15. biofilm and intracanal dressing or. analyzed the efficacy of $3 \% \mathrm{NaOCl}, 10 \%$ povidone iodine, $0.2 \%$ chlorhexidine, $17 \%$ EDTA and calcium hydroxide on a clinical isolate of $E$. faecalis grown as biofilm or planktonic suspension phenotype. The difference in gradients of bacterial killing amongst the biofilm, planktonic suspension or pellet presentation was significant and dependent upon the agent, except for $\mathrm{NaOCl}$ and calcium hydroxide, in which no difference could be detected. $\mathrm{NaOCl}$ was the most effective agent and achieved $100 \%$ killing for all presentations of E. faecalis after a 2-min contact time. Estrela, et al. ${ }^{11}$ (2007) determined the antimicrobial efficacy of ozonated water, gaseous ozone, sodium hypochlorite and chlorhexidine in E. faecalis biofilm. The irrigation solutions tested for $20 \mathrm{~min}$ were not sufficient to inactivate $E$. faecalis. Nair, et al. ${ }^{30}$ (2005) suggested the need of non-antibiotic chemomechanical measures to treat teeth with infected and necrotic root canals so as to disrupt the biofilm.

Relevant clinical considerations are yet to be elucidated, such as the efficacy of intracanal medicament on bacterial biofilm, the time necessary for a mature endodontic biofilm to form or the ideal biofilm model to assess antimicrobial endodontic substances. The purpose of this paper is to make a critical analysis of the published research on the antibacterial efficacy of intracanal medicaments on bacterial biofilm.

\section{MATERIAL AND METHODS}

\section{Search Strategy}

This work was developed based on an analysis of longitudinal studies from a quantitative systematic review of results of several investigations. English-language articles were' retrieved from electronic biomedical journal

TABLE 2- Inclusion and exclusion criteria for selection of the articles

\section{Inclusion criteria}

1. In vivo studies, in humans

2. Related to the root canal biofilm

3. Randomized controlled trials (RCT)

4. Related to the efficacy of intracanal medicaments on biofilm

5. English-language articles

\section{Exclusion criteria}

1. In vitro studies

2. Studies performed in animals

3. Studies related only to microbial identification

4. Studies not related to the efficacy of intracanal medicaments on endodontic biofilm

5. Studies related to the periapical biofilm

6. Studies related to the non-endodontic biofilm

7. Studies only with abstract or with no available abstract

8. Literature reviews

9. Case reports 
databases and handsearching records. Prospective studies were reviewed with regard to the efficacy of the intracanal medicaments on bacterial biofilm. The following databases were searched on August $1^{\text {st }}$ of 2007: MEDLINE (without filter, from 1966 to August $1^{\text {st }}$ of 2007), EMBASE (without filter, from 1980 to August $1^{\text {st }}$ of 2007), Cochrane Oral Health Group Trials Register and Cochrane Central Register of Controlled Trials (CENTRAL). For the electronic search strategy the terms presented in Table 1 were used as keywords in several combinations.

Handsearching was conducted by the review of the reference lists of the eligible clinical trials and the review of author's personal databases of trial reports in an attempt to identify any other relevant studies.

\section{Study Selection}

The selected articles were identified from titles, abstracts and full-text articles by two independent reviewers, considering the tabulated inclusion and exclusion criteria. Disagreements were resolved by consensus. Table 2 shows the inclusion and exclusion criteria for selection of the articles.

\section{RESULTS}

Based on the inclusion and exclusion, 91 articles were selected, of which $17(18.7 \%)$ were literature reviews, 8 $(8.8 \%)$ referred to in vivo studies (7 in humans and 1 in animals), 19 (20.1\%) referred to in vitro studies [7 (7.7\%) articles of biofilm in membrane filter models and $12(13.1 \%)$ articles on root dentin biofilm models], $9(10 \%)$ were studies on nonendodontic biofilm, and $33(36.2 \%)$ articles related to other types of study (Figure 1).

None of the 8 articles referring to in vivo studies met all inclusion criteria (Table 3). Table 4 describes in vitro research articles that were excluded for referring to different bacterial biofilm models, contamination time, root canal cleaning and shaping techniques, and therapeutic efficacy.

No article selected in a preliminary review by handsearching met the inclusion criteria either. The results of the analysis demonstrated inefficacy of intracanal medicaments on bacterial biofilm.

\section{DISCUSSION}

Systematic reviews, associated or not to meta-analyses, represent major positions at the evidence pyramid towards a direct decision making, capable to indicate clinical procedures certificated by more trustable arguments. The major difficulty found in the present study was the great deal of available information, and the large number of investigations with agreeing and disagreeing conclusions. Scientifically based evidence that confirms the efficacy of intracanal medicaments on bacterial biofilm involves a profound reflection and discussion, regardless of the limits and caution with the methodology $y^{16,17,21,36,43}$. Longitudinal studies signalize that there is yet no accurate solution to eliminate or disrupt the root canal bacterial biofilm. However, the results of this critical review confirmed that root canal preparation, with careful disinfection and use of intracanal substances that provide good antimicrobial efficacy, tissue dissolution capacity, and acceptable biocompatibility, will definitely improve the prognosis of the treatment of apical periodontitis ${ }^{25,30}$.

From a total of 91 articles, $8.8 \%$ referred to in vivo studies (Figure 1), but no article fulfilled all inclusion criteria

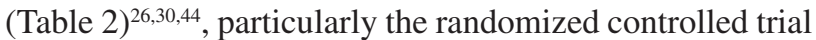
studies.

TABLE 3- Excluded in vivo research articles

\begin{tabular}{|c|c|c|c|c|c|c|}
\hline Author (ref.) & $\begin{array}{l}\text { Number of } \\
\text { samples }\end{array}$ & $\begin{array}{l}\text { Exclusion } \\
\text { Criteria }\end{array}$ & Intervention & $\begin{array}{l}\text { Number of } \\
\text { sessions }\end{array}$ & $\begin{array}{l}\text { Observation } \\
\text { model }\end{array}$ & Outcome \\
\hline Nair,et al. ${ }^{30}$ (2005) & 16 & 3 & $\begin{array}{l}\text { Root canal } \\
\text { preparation + } \\
5.25 \% \mathrm{NaOCl} \\
+17 \% \mathrm{EDTA}\end{array}$ & One-visit & LEM, TEM & $\begin{array}{l}\text { Non } \\
\text { efficacy }\end{array}$ \\
\hline Araki, et al. ${ }^{2}$ (2006) & - & $3,4,5$ & Er:YAG Laser & - & SEM & Efficacy \\
\hline $\begin{array}{l}\text { Khemaleelakul, et al. }{ }^{22} \\
\text { (2006) }\end{array}$ & 10 & 3,4 & - & - & $\begin{array}{c}\text { Visual, Fluorescent } \\
\text { dye-staining }\end{array}$ & - \\
\hline Noguchi, et al. ${ }^{31}$ (2005) & 27 & $3,4,5$ & - & - & Immunohistochemical & - \\
\hline Leonardo, et al. ${ }^{26}$ (2002) & 21 & $3,4,5$ & - & - & SEM & - \\
\hline Noiri, et al. ${ }^{32}$ (2002) & 6 & $3,4,5$ & - & - & SEM & - \\
\hline Tronstad, et al. ${ }^{44}$ (1990) & - & $3,4,5$ & - & - & SEM & - \\
\hline
\end{tabular}

LEM - light electron microscopy, TEM - transmission electron microscopy, SEM - scanning electron microscopy. (http://www.ncbi.nlm.nih.gov/PubMed) 


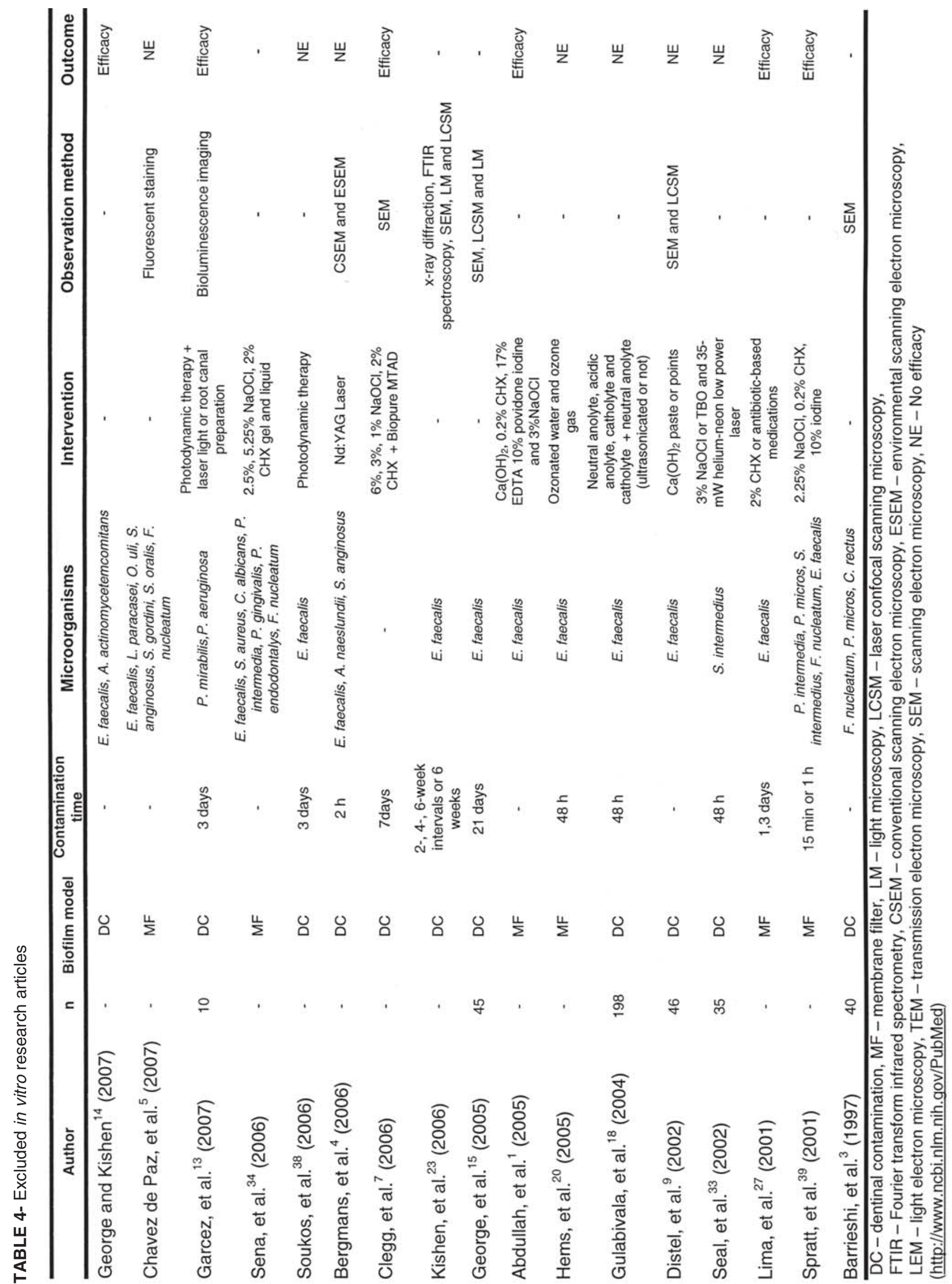


Interestingly, a recently published study contemplating the clinical aspects about the bacterial biofilm is the only one with high level of evidence. Nair, et al. ${ }^{30}$ (2005) assessed intracanal microbial status of apical root canal system of mesial roots of human mandibular first molars with primary apical periodontitis immediately after one-visit endodontic treatment. The findings highlight the importance and need for stringently applying non-antibiotic chemomechanical measures in order to disrupt the biofilm and reduce the intraradicular microbial load to the lowest possible level to ensure the most favorable long-term prognosis for treatment of infected root canals. In accordance with this study, other investigations also recovered microorganisms from teeth with endodontic infection after antimicrobial endodontic therapy ${ }^{6,41}$.

The findings of in vitro studies (Table 4) show an antimicrobial effectiveness of intracanal medicaments on bacterial biofilm ${ }^{1,39}$ similarly to in vivo evaluations involving the presence of biofilm on all external root apex surfaces in teeth with pulp necrosis with periapical lesions ${ }^{26}$. Most studies about endodontic biofilm are in vitro experiments. Therefore, care should be taken to avoid inappropriate extrapolation of results, which does not allow a clinical decision for therapeutic protocols in humans. It is mandatory to consider the role and importance of biofilm in endodontics, as well as its definition.

Considerable differences were observed in biofilm models and in the time required for its development (Tables 3 and 4). In the present study, it was not possible to obtain an ideal combination of results, considering the high heterogeneity of the adopted clinical protocols. This fact limited the performance of a meta-analysis.

The large number of published papers can bring in its context contradictory conclusions. The variability between the employed methodologies, study selection, publication biases, absence of randomized controlled trial, access to all the information of the published experiments and the own nature of the essays, signalizes for some critical implications towards the equation of the problem.

A clinical question that supports the decision about the antibacterial efficacy of intracanal medicaments on bacterial biofilm cannot be answered using a critical longitudinal analysis of published articles. Various obstacles on the analysis of the pertinent data for the included studies involved methodological data that were hidden and that present a relative degree of importance. Relevant aspects of the studies that met the inclusion criteria were considered, such as the experimental model and sample size, the time lapsed from the initial endodontic treatment until the present moment, the method of identification of the bacteria, the presence of bacteria on the initial samples, the chemical substances used during the root canal disinfection, the time of maintenance of the intracanal dressing prior to obturation, and the efficacy of the medicaments against the tested bacteria. However, the difficulty for comparing these studies was due to differences in the adopted treatment strategies, as follows: standardization of the amount of dentin removal after emptying the root canal; the choice of the preparation technique; tooth type and sample size; characteristics and technique of placement of the test materials; confirmation of complete root canal filling; quality control of the irrigation solutions as well as variations in their concentration; biofilm model; time for microbial colonization; criteria for the detection of the periapical lesion, among others.

Despite all known limitations, studies that are not developed in humans are also relevant because, prior to clearance for human use, biological evaluations of dental materials, initial and secondary tests are required ${ }^{40}$. Other aspects that must be critically observed and judiciously analyzed are the biofilm model to test the antimicrobial endodontic medicaments, the biological indicator, and the time necessary for biofilm formation.

Socransky and Haffajee ${ }^{37}$ (2002) reported that the reason for the existence of a biofilm is that it allows microorganisms to stick to and multiply on surfaces. Thus, attached bacteria (sessile) growing in a biofilm display a wide range of characteristics that provide a number of advantages over single-cell (planktonic) bacteria. A major advantage is the protection that the biofilm provides to colonizing species from microorganisms competing for environmental factors, such as host defense mechanisms, and from potentially toxic substances in the environment, such as lethal chemicals or antibiotics. Biofilms can also facilitate processing and uptake of nutrients, cross-feeding (one species providing nutrients to another), removal of potentially harmful metabolic products (often used by other bacteria) as well as the development of an appropriate physicochemical environment (such as a properly lowering the oxidation reduction potential).

Bacterial biofilm has an open architecture with channels traversing from the biofilm surface. This structure affects the movement of molecules and gradients in key determinants develop. Bacteria growing on a surface display a novel phenotype, one of the consequences being an increased resistance to antimicrobial agents. Resistance can result from restricted inhibitor penetration, slower bacterial growth rates, transfer of resistance genes, suboptimal environmental conditions for inhibitor activity, and the expression of a resistant phenotype ${ }^{29}$. Duggan and Sedgley ${ }^{10}$ tested the hypothesis that the ability of E. faecalis to form biofilm is related to the source of the strains. The variations observed in these clinical isolates suggested that biofilm formation might be an important factor when considering the virulence phenotype of endodontic strains in general.

Chávez de Paz, et al. ${ }^{5}$ (2007) evaluated the possible role of biofilm communities. Changes in the environment, such as calcium hydroxide-related $\mathrm{pH}$ increase or the effect of antimicrobials, are capable of triggering genetic cascades that modify the physiological characteristics of bacterial cells. Surface adherence by bacteria to form biofilms is a good example of bacterial adaptation. More information is now available about the existence of polymicrobial biofilm communities on root canal walls coupled with new data showing that the adaptive mechanisms of bacteria in these biofilms are significantly augmented for increased survival. This ecological view on the persisting infection problem in 
endodontics suggests that the action of individual species in refractory endodontic infections is secondary when compared to the adaptive changes of a polymicrobial biofilm community undergoing physiological and genetic changes in response to changes in the root canal environment.

The invasion of root dentinal tubules by root canal bacteria is a multifactorial event in which a limited number of oral bacterial species have the required properties to participate ${ }^{28}$. The penetration of microorganisms in infected root dentin have shown variations considering the experimental model, the biological indicator and the time of incubation employed in the studies (Table 4). Distel, et al. ${ }^{9}$ (2002) presented evidence of E. faecalis colonization and biofilm formation in root canals of human teeth. In order to develop new treatments to eradicate E. faecalis from persistent root canal infections, the mechanisms through which this microorganism maintains these infections must be understood.

\section{CONCLUSION}

For all reasons addressed in this paper, and considering the heterogeneity of guidelines to study antimicrobial strategies for endodontic infections and the high clinical success estimate, adequate disinfection assisted by the intracanal medicaments reduces the bacterial population and favors the prognosis. The antimicrobial efficacy of intracanal medicaments on bacterial biofilm still needs to be confirmed. Further studies are required to offer new guidelines for the treatment protocol of endodontic biofilm.

\section{REFERENCES}

1- Abdullah M, Ng Y-L, Gulabivala K, Moles D, Spratt DA. Susceptibilties of two Enterococcus faecalis phenotypes to root canal medications. J Endod. 2005;31:30-6.

2- Araki AT, Iraki Y, Kawakami T, Lage-Marques JL. Er:Yag laser irradiation of the microbiological apical biofilm. Braz Dent J. 2006;17:2969.

3- Barrieshi KM, Walton RE, Johnson WT, Drake DR. Coronal leakage of mixed anaerobic bacteria after obturation and post space preparation. Oral Surg Oral Med Oral Pathol Oral Radiol Endod. 1997;84:310-4.

4- Bergmans L, Moisiadis P, Teughels W, Van Meerbeek B, Quirynen M, Lambrechts P. Bactericidal effect of Nd:YAG laser irradiation on some endodontic pathogens ex vivo. Inter Endod J. 2006;39:547-57.

5- Chávez de Paz LE, Bergenholtz G, Dahlén G, Svensäter G. Response to alkaline stress by root canal bacteria in biofilms. Int Endod. J. 2007;40:34455 .

6- Chávez de Paz LE, Dahlén G, Molander A, Moller A, Bergenholtz G. Bacteria recovered from teeth with apical periodontitis after antimicrobial endodontic treatment. Int Endod J. 2003;36:500-8.

7- Clegg MS, Vertucci FJ, Walker C, Belanger M,Britto LR. The Effect of Exposure to irrigant solutions on apical dentin biofilms in vitro $\mathrm{J}$ Endod. 2006;32:434-7.
8- Costerton JW, Cheng KJ, Geesey GG, Ladd TI, Nickel C, Dasgupta M, et al. Bacterial biofilms in nature and disease. Ann Rev Microbiol. 1987;41:435-64.

9- Distel JW, Hatton JF, Gillespie MJ. Biofilm formation in medicated root canals. J Endod. 2002;28:689-93.

10- Duggan JM, Sedgley CM. Biofilm formation of oral and endodontic Enterococcus faecalis. J Endod. 2007;33:815-8.

11- Estrela C, Estrela CRA, Decurcio DA, Hollanda ACB, Silva JA. Antimicrobial efficacy of ozonated water, gaseous ozone, sodium hypochlorite and chlorhexidine in infected human root canals. Int Endod J. 2007;40:85-93.

12- Evans M, Davies JK, Sundqvist G, Figdor D. Mechanisms involved in the resistance of Enterococcus faecalis to calcium hydroxide. Int Endod J. 2002;35:221-8

13- Garcez AS, Riberio MS, Tegos GP, Nunez SC, Jorge AO, Hamblin MR. Antimicrobial photodynamic therapy combined with conventional endodontic treatment to eliminate root canal biofilm infection. Lasers Surg Med. 2007;39:59-66.

14- George S, Kishen A. Photophysical, photochemical, and photobiological characterization of methylene blue formulations for lightactivated root canal disinfection. J Biomed Opt. 2007;12:034029.

15- George S, Kishen A, Song KP. The role of environmental changes on monospecies biofilm formation on root canal wall by Enterococcus faecalis. J Endod. 2005;31:867-72.

16- Giardino L, Ambu E, Savoldi E, Rimondini R, Cassanelli C, Debbia EA. Comparative evaluation of antimicrobial efficacy of sodium hypochlorite, MTAD, and Tetraclean against Enterococcus faecalis biofilm. J Endod. 2007;33:852-5.

17- Glenny AM, Esposito M, Coulthard P, Worthington HV. The assessment of systematic reviews in dentistry. Eur J Oral Sci. 2003;111:8592.

18- Gulabivala K, Stock CJ, Lewsey JD, Ghori S, Ng YL, Spratt DA. Effectiveness of electrochemically activated water as an irrigant in an infected tooth model. Int Endod J. 2004;37:624-31.

19- Haapasalo M, Ørstavik D. In vitro infection and disinfection of dentinal tubules. J Dent Res. 1987;66:1375-9.

20- Hems RS, Gulabilavala K, Ng Y-L, Ready D, Spratt DA. An in vitro evaluation of the ability of ozone to kill a strain of Enterococcus faecalis. Int Endod J. 2005;38:22-9.

21- Jadad AR, Cook DJ, Browman GP. A guide to interpreting discordant systematic reviews. Can Med Assoc J. 1997;156:1411-6.

22- Khemaleelakul S, Baumgartner JC, Pruksakom S. Autoaggregation and coaggregation of bacteria associated with acute endodontic infections. J Endod. 2006;32:312-8.

23- Kishen A, George S, Kumar R. Enterococcus faecalis-mediated biomineralized biofilm formation on root canal. J Biomed Mater Res A. 2006;77:406-15.

24- Kristich CJ, Li YH, Cvitkovitch DG, Dunny GM. Esp-Independent biofilm formation by Enterococcus faecalis. J Bacteriol. 2004;186:15463.

25- Law A, Messer H. An evidence-based analysis of the antibacterial effectiveness of intracanal medicaments. J Endod. 2004;30:689-94.

26- Leonardo MR, Rossi MA, Silva LAB, Ito IY. EM evaluation of bacterial biofilm and microorganisms on the apical external root surface of human teeth. J Endod. 2002;28:815-8. 
27- Lima KC, Fava LRG, Siqueira-Jr JF. Susceptibilities of Enterococcus faecalis biofilms to some antimicrobial medications. J Endod. 2001;27:616-9.

28- Love RM. Invasion of dentinal tubules by root canal bacteria. Endod Top. 2004;9:52-65.

29- Marsh PD. Plaque as a biofilm: pharmacological principles of drug delivery and action in the sub- and supragingival environment. Oral Dis 2003;9:16-22.

30- Nair PNR, Henry S, Cano V, Vera J. Microbial status of apical roo canal system of human mandibular first molars with primary apical periodontitis after one-visit-endodontic treatment. Oral Surg Oral Med Oral Pathol Oral Radiol Endod. 2005;99:231-52.

31- Noguchi N, Nori Y, Narimatsu M, Ebisu S. Identification and localization of extraradicular biofilm-forming bacteria associated with refractory endodontic pathogens. Appl Environ Microbiol. 2005;71:873843.

32- Noiri Y, Ehara A, Kawahara T, Takemura N, Ebisu S. Participation of bacterial biofilms in refractory and chronic periapical periodontitis. J Endod. 2002;28:679-83.

33- Seal GJ, Ng Y-L, Spratt D, Bhatti M, Gulabivala K. An in vitro comparison of the bactericidal efficacy of lethal photo - sensitization or sodium hyphochlorite irrigation on Streptococcus intermedius biofilms in root canals. Int Endod J. 2002;35:268-74.

34- Sena NT, Gomes BP, Vianna ME, Berber VB, Zaia AA, Ferraz CC, et al. In vitro antimicrobial activity of sodium hypochlorite and chlorhexidine against selected single-species biofilms. Int Endod J. 2006;39:878-85.

35- Siqueira JF Jr, Batista MMD, Fraga RC, Uzeda M. Antibacterial effects of endodontic irrigants on black-pigmented Gram-negative anaerobes and facultative bacteria. J Endod. 1998;24:414-6.

36- Siwek J, Gourlay ML, Slawson DC, Shaughnessy AF. How to write an evidence-based clinical review article. Am Fam Physician. 2002 65:258-68

37- Socransky SS, Haffajee AD. Dental biofilms: difficult therapeutic targets. Periodontology 2000. 2002;28:12-55.

38- Soukos NS, Chen PS, Morris JT, Ruggiero K, Abernethy AD, Som S, et al. Photodynamic therapy for endodontic disinfection. J Endod. 2006;32:979-84

39- Spratt DA, Pratten J, Wilson M, Gulabivala K. An in vitro evaluation of the antimicrobial efficacy of irrigants on biofilms of root canal isolates. Int Endod J. 2001;34:300-7.

40- Stanley HR. Toxicity testing of dental materials. Boca Raton, FL CRC Press; 1985.

41- Sundqvist G, Figdor D, Persson S, Sjögren U. Microbiologic analysis of teeth with failed endodontic treatment and the outcome of conservative re-treatment. Oral Surg Oral Med Oral Pathol Oral Radiol Endod. $1998 ; 85: 86-93$

42- Svensäter G, Bergenholtz G. Biofilms in endodontic infections. Endod Top. 2004;9:27-36

43- Torabinejad M, Bahjri K. Essential elements of evidenced-based endodontics: steps involved in conducting clinical research. J Endod. $2005 ; 31: 563-9$

44- Tronstad L, Kreshtool D, Barnett F. Microbiological monitoring and results of treatment of extraradicular endodontic infection. Endod Dent Traumatol. 1990;6:129-36.
45- Wilson M. Susceptibility of oral bacterial biofilms to antimicrobial Agents. J Med Microbiol. 1996;44:79-87. 